\title{
An Evaluation of the Colors in Primary School English Textbook through Students' Perceptions
}

\author{
Sara Kasmaienezhad-Fard (Corresponding author) \\ Faculty of Educational Studies, University Putra Malaysia (UPM) \\ 43400, Serdang, Selangor, Malaysia \\ E-mail: sara_kasmaie@yahoo.com
}

Tajularipin Sulaiman

Faculty of Educational Studies, University Putra Malaysia (UPM)

43400, Serdang, Selangor, Malaysia

E-mail: tajulas@upm.edu.my

\begin{abstract}
Nor Hayati Alwi
Faculty of Educational Studies, University Putra Malaysia (UPM)

43400, Serdang, Selangor, Malaysia

E-mail: nalwi@upm.edu.my
Ahmad Fauzi MohdAyub
Faculty of Educational Studies, University Putra Malaysia (UPM)
43400, Serdang, Selangor, Malaysia
E-mail: afmy@upm.edu.my

Received: August 1, 2017 Accepted: Sep. 18, 2017 Published: November 1, 2017

doi:10.5296/jse.v7i4.11966 URL: https://doi.org/10.5296/jse.v7i4.11966 


\section{Abstract}

The Malaysian education system has transformed from the traditional to the modern, albeit keeping to textbooks as the main teaching material. Among the factors determining the quality of textbooks, color is an important one, especially in primary school textbooks. Suitably applied, it will enrich classroom instruction and aid the learning process. This research was designed to run in two phases, and the data collected were analyzed by SPSS software. In the first phase, the colors used in the pictures of Year-4 English textbook were evaluated. Next, the color preferences of 384 students in the fourth grade of national primary schools were collected. Data from the first phase show that out of 901 textbook pictures, 792, 733, and 412 respectively use primary, secondary, and tertiary colors. Data from the second phase show the students highly interested in tertiary colors. The results of this study reveal important points for textbook quality improvement. Knowing what colors students like allows illustrators to consider age levels, not only when illustrating textbooks but also when creating pictures for other materials.

Keywords: content analysis, textbook, color theory, student preference, descriptive analysis. 


\section{Introduction}

With its direct influence, color is considered an important element of design. The importance of color has been studied in various aspects; among them, its impact on the physical systems of the human body (Torrice \& Logrippo, 1989), and the relationship between color and energy level as well as mood (Kueller \& Mikellides, 1993). The role of color in education has not been overlooked. A lot of studies discuss color and its relationship with aspects of education, for instance, students' motivation (Otto \& Askov, 1968); age and color preference to surrounding environments(Jalil, Yunus, \& Said, 2013);students' attention level and their cognitive and learning abilities (Jalil et al., 2013);memory performance and attention keeping (Kim, 2010); and emotion as well as academic performance(Gaines \& Curry, 2011).The study of colors is complicated; such studies obtain varying results. Studies of colors may differ on the age, gender, context, and conditions of their participants (Jalil et al., 2013).

According to a study by Shapiro, Ward and Vetter (1995), adding colors to classroom instruction can enhance students' performance. Buckingham and Harrower (2007) state that color application to classroom instruction is sometimes only for getting the attention of students, especially the ones in primary grades. Their study on primary students in Grades 4 and 5 reveal that the students are more interested in colored maps with saturated colors than they do with black and white ones (Buckingham \& Harrower, 2007). Nonetheless, Piaget states that as children grow, their focus on color and shape decreases, as it increases on characteristics such as form (Otto \& Askov, 1968). Mahnke (1996)believes that pictures with many colors are useful in attracting young children of elementary grades. He also confirms that light colors and highly chromatic contrast ones are more appealing to younger students (Mahnke, 1996).

In recent study on evaluating visual elements in two EFL textbook by Roohani and Sharifi(2015), evaluated visual elements of Interchange 3 and Top Notch 3B. They analyzed illustrations in terms of the balance of colors namely black and white, color drawings and photos to investigate to what degree visual materials are utilized for decorative goals. The results showed that the most of the portrayals were color photos, and drawings in order to show actions appropriately and practically. The results of the study by Fauzi, et al (2015) highlights the key issues in exploring and experimenting the new changes in illustration, from the old conventional black and white to the enjoyable expressive color illustration.

Regardless of the relationship between the students' age and their color preference, there is another important element of the relationship between gender and color preference. One study shows that despite yellow and blue being two favorite colors of students, the students' gender does not influence the preference(Praphamontripong, 2010). Another study on American college students states that males are more inclined to blue, while females tend equally to both green and blue(Ellis \& Ficek, 2001). According to another study (Jalil et al., 2013), both female and male favorite colors are blue, green, and purple, and that pink and blue are respectively preferred by females and males.

To young children, colored textbooks are usually more attractive than plain black-and-white ones. Praphamontripong's(2010) study of the role of color saturation in textbook maps found that elementary students of Grades 4 and 5 strongly prefer color-saturated maps as opposed to 
black-and-white ones. His review of past studies also indicates that blue is the most preferred color whereas yellow the least favored and that such preferences remain consistent over time. The preference for colored textbooks thus seems to vary across ages and educational levels. In general, colored illustrations tend to attract the attention of younger and less educated children (Hartley, 2013).

In some home libraries, textbooks are the first kind of books making their way to the shelves. According to Kesea and Aydin (2007), a textbook is an environment, along with the teacher and the board, conveying 99 percent of the information communicated. This just emphasizes the importance of textbooks to a student's personality development. They become the tool for improvement of a student's communication skills: thinking, interpreting, listening,speaking,reading, andwriting;also for development of positive social attitudes such as enjoying working; respecting human values, and fraternizing between nations (Keser \& Aydin, 2007).

Textbooks are important instructional materials that pupils and teachers depend on for the learning process (Kiai, 2012). They are used by teachers, students, and administers alike but what makes for a good/standard textbook differs from group to group. Who to turn to for reliable advice behind an informed decision on suitable textbooks remains a question (Ansary $\&$ Babaii, 2002). Textbooks that are well-written and well-designed are crucial predictors of student learning and can contribute effectively to classroom teaching. Such textbooks aid effective use of instructional time and classroom teaching strategies, playing a fundamental role as they do in curriculum policy and implementation and more generally in mass education (Crossley \& Murby, 1994; Praphamontripong, 2010).

This research divides into two phases. In the first phase, the colors used in Malaysian national school Primary-Year-4 English textbook are analyzed by content analysis. An instrument is designed to investigate the colors used in the visual parts of the textbook (i.e., the pictures included in the textbook). In the second phase, the preferences of Year-4students for the colors are determined through a survey among the students. A pictorial questionnaire is another instrument, designed to solicit survey data from the students. Both phases are analyzed by quantitative approaches and the results are discussed. The rest of the paper is organized as follows: Section 2 presents the color theory, Section 3 discusses the methodology of the research, Section 4 presents the results, and Section 5 concludes.

\section{Textbook content analysis}

Content analysis is a research technique for making replicable and valid inferences from texts (or other meaningful matter) in the contexts of their use (Krippendorff, 2004). Content analysis can be used to interpret written text, spoken text, and visual images (Hawley, 2009). Generally, quantitative content analysis can be said as a technique that allows researchers to analyze qualitative data (Starosta, 1984). Quantitative content analysis (QCA) is a specific method for analyzing content with a clear focus on quantification of qualitative data (Riffe, 2005).

The aim of content analysis is to give information and ideas, depict realities, and guide acts by making reproducible and valid inferences from the data to its context (Downe Wamboldt, 
1992). Its main objective is to achieve a condensed and extensive explanation of phenomena so the concepts or the categories explaining the phenomena can be created.

Content analysis was originally designed for use with texts, though it is now generally admitted as a valid method for scrutinizing visual messages, mainly when looking for patterns in a large sample (Rose, 2007). According to Stempel (1989), content analysis is a method for analyzing symbolic content. In current research, the content analysis is limited to the colors of pictures in theYear-4 primary school English textbook used in Selangor, Malaysia.

An important concept in quantitative content analysis is "Systematic and Replicable"; before starting the analysis, the researcher should implement it as requested in the data sample (Krippendorff, 2004; Riff, Lacy, \& Fico, 2014). This is made by coding - creating a series of operating rules that specify the meaning and extent or intensity of various elements.

Content analysis is built on a system of predefined codes or categories. The researcher makes these codes for two main reasons: one, to evaluate and analyze each sample systematically in the same way so the findings can be compared; two, to allow other researchers a replicable analysis in future. Researchers should extend and implement a range of codes based on the research questions in their study. When these codes have been determined, one would be able to go through a series of elements and analyze each one systematically through exact, pre-determined codes that help answer questions. By well-defined and determined codes, anybody trained in coding must be able to replicate the findings of the original analyst. Someone might do a statistical analysis on a variety of elements by using the codes as variables.

The next issue in content analysis relates to categories. Dey (1993) notes that making categories is not about bringing similar observations together; instead, data are classified according to its 'belongingness' to an exact group; this involves a comparison of data, even data that do not belong to the same group. The main purpose of making categories is to supply a way to explain phenomena, increase awareness, and generate knowledge (Elo \& Kyngas, 2008; Graneheim \& Lundman, 2004). In this study, the colors of pictures are considered as categories. Another important issue in content analysis is "unit". The definition of units in the analysis, however, is rather unclear, that their discrimination becomes hard. In the current study, each picture in each page of textbook is considered as a unit.

According to Riffe et al. (2014), the objective or intended result of using content analysis in quantitative approach is another point which the researcher has to determine before starting the analysis. Two kinds of objectives are found: 1) for making descriptive statistical analysis from a large dataset, and, 2) for creating inferences from the data to its production or consumption context. Riffe et al. (2014)reminds that the purpose should be apparent in the research questions before the analysis is conducted. The purpose of the researcher in this study is to systematically analyze the colors of the textbook pictures.

\section{Basic colour theory}

Color theory has numerous concepts, definitions, and design applications but only three of its basic categories are more logical and useful: color wheel, color harmony, and color usage 


\section{Macrothink}

context. The focus of this study is the color wheel.

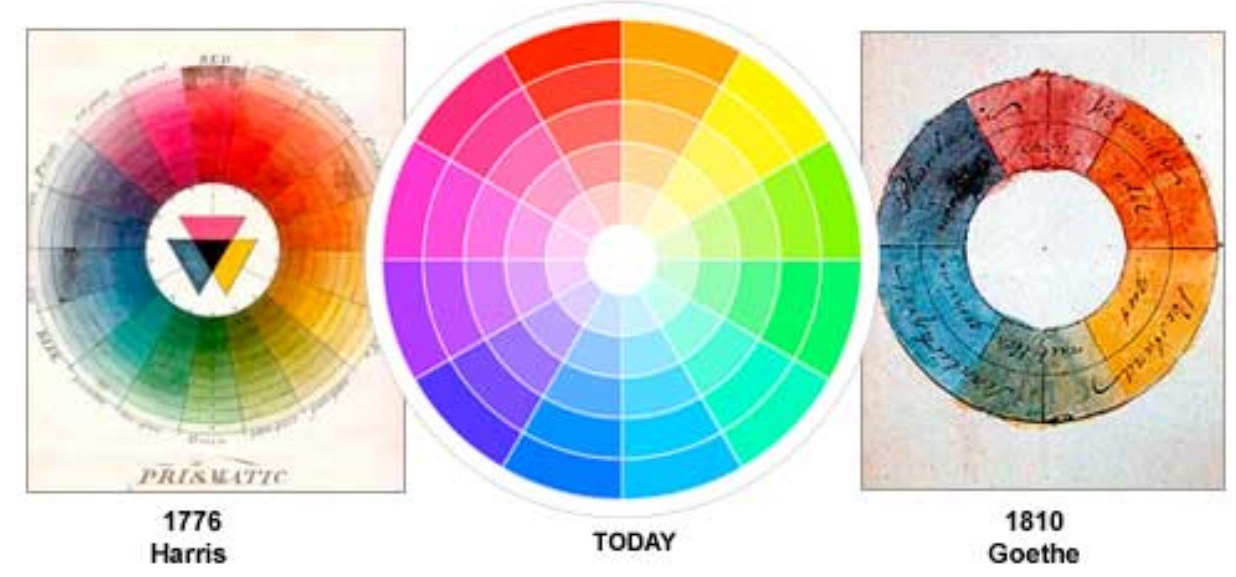

Figure 1. Color wheel providing the basis for color definitions or categories

The color circle of reds, yellows, and blues is traditional to art. Sir Isaac Newton was the first to develop the circle of colors, which was in 1666. Newton (1642 - 1727) formulated the laws of color mixing, from his discovery that shining a white light through two prisms refracts the light into its spectral hues. The color wheel developed is based on the seven wavelengths of the visual spectrum (Bell, 2013). Numerous variations of it have been studied and designed since then, and the validity of one format over the other debated on. However, any circle or wheel of colors witha sequence of pure hues arranged logically is valid (Westfall, 1962) (Figure 1).
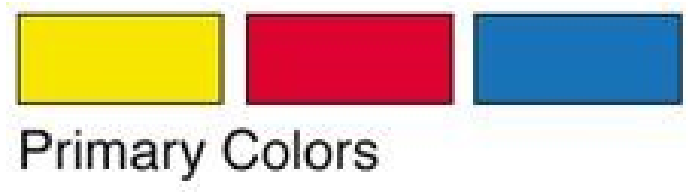

\section{Primary Colors}
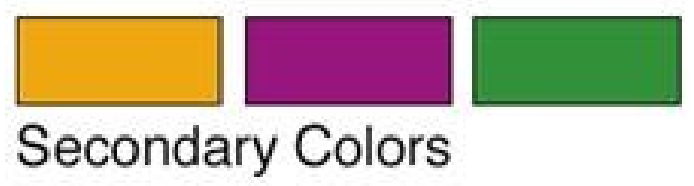

\section{Secondary Colors}

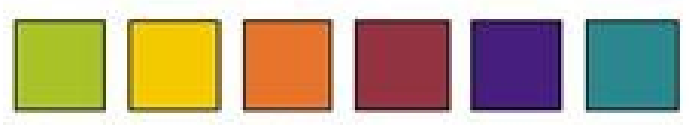

\section{Tertiary Colors}

Figure 2. Categories of Colors

In this study, the colors are divided into three groups based on the color wheel. All pictures of the textbook are analyzed (in phase I of the research) according to the following classifications and as shown in Figure 2.

Primary Colors: these colors do not form by combining with other colors; no mixture of colors will recreate them. They comprise the pigments of red, yellow, and blue in traditional color theory. Other colors are derived from them. 
Secondary Colors: a mixture of the primary colors will produce these secondary colors, which include green, orange, and purple.

Tertiary Colors: these colors are mixtures of primary and secondary colors (hence, their two-word names of yellow-orange, red-orange, red-purple, or blue-purple, for example).

\section{Methodology}

The main objective of this research is an evaluation of the colors used in primary-year-four English textbook through the perceptions of students in the State of Selangor, Malaysia. The researcher designed this study on quantitative measures, to discover the current situation of textbook colors and also to find the students' color preferences.

\section{Research design}

The study was done in two phases. Phase I is content analysis of the Year-4 English textbook, and phase $\Pi$ is a descriptive survey among the Year-4 students. In the first phase, the colors of the pictures in the textbook were analyzed quantitatively to learn their current situation. The second phase of the study discovered the students' color preferences through a survey and again quantitatively.

\section{Population and Sampling}

In phase I, the Primary-Year-4 English textbook of the national schools was selected as the subject of the research sample. The researcher chose this particular primary textbook for several reasons;1) In terms of Piaget's concept of concentration, a young child pays attention only to the dominant characteristic of a configuration and to color (Corah, 1964); 2) Compared with the students in the first few years of primary school, students in the last few years are more mature; their understanding of colors of pictures improves as does their communication (more effective) with the researcher; 3) The students in the last years of primary school have to be prepared for the UPSR examination, an important national public examination in Malaysia. Preparation for the UPSR begins at the Primary-Year-4 level so the students, the teachers, and the whole education system at this level face the minimum effects of UPSR; 4) Compared with students at the lower grades, students at this grade should be more proficient in the English language, thus can communicate better with the researcher; 5) The researcher is not proficient in Bahasa Malaysia, and recruiting a translator would be costly, therefore, the English textbook was chosen as the research sample.

In phase II, the design of the study required the data to be collected from the primary-school students. The researcher collected data from the students in the primary schools of the Malaysian State of Selangor, which, with its large population, ranks first among all Malaysian states and is also information-rich. According to the Selangor State Education Department, in2016 there were 60,118 Primary-Year-4students in this particular state; among them, 30,893 boys and 29,225girls. The researcher used Cochran's formula (1977)to approximate the population sample size, which in this study was 384 students. 
Instrumentation

The researcher designed two instruments to collect the data in phases I and II.

In Phase I, the researcher developed an original coding sheet to guide the analysis. Since the colors of the textbook pictures were to be investigated, an identification number was given to each picture unit. The units were then coded according to the color categories (based on the color theory):primary colors, secondary colors, tertiary colors, and colors that do not belong to the first three groups, which included white, black, cream, and grey.

In phase II, a self-managed questionnaire in the form of a booklet was developed to collect the data. The booklet used the primary colors, the secondary colors, and the tertiary colors from the color wheel. At least one set of pictures with the colors of all the categories was necessary. Three simple objects comprising house, car, and shoes were taken into consideration, and three sets of pictures with these objects were prepared. All the sets were shown to the students, who were asked to select a specific number of colors as his/her favorite colors in each set.

\section{Validity and Reliability}

Reliability is associated with consistency of the collected data (Ary et al. 2006). As reported by Ary et al. (2006), a reliable measuring instrument is not necessarily valid, but to be valid it should be reliable. Bothreliability and validity are thus important. The validity of an instrument is how suitably the instrument measures a variable in order to know the domain of the variable. Validity analysis is essential for the development and evaluation of the measuring instruments.

A panel of ten experts was engaged to check the validity of the instruments: six from the Ministry of Education Malaysia who are experts in the subject of educational textbook pictures, and four from the education field.

The data reliability was investigated in two phases. In the first phase, two inter-coders including the researcher carried out a part of content analysis and tested the results by Kappa to ensure high reliability of the research. In the second phase, the reliability of two inter-raters was determined through Pearson correlation by SPSS software.

\section{Data Analysis}

Statistic Package for Social Science (SPSS) version 11.0 was used for the quantitative data analysis. In the first phase of this study, the contents of the Primary-Year-4 English textbook was analyzed based on the colors used. The descriptive statistics including frequency and percentages were calculated in order to find out the current situation of the textbook colors. In the second phase of the study, descriptive statistics was used to determine the distribution of the variables including the color categories. Frequency and chi-square test results were identified for all the variables to obtain a deep understanding of the data.

\section{Results}

This section details the results based on the research phases. For each phase, the statistical analysis results are discussed. 
Phase I

The goal of Phase I was to analyze the colors used in the Primary-Year-4 English textbook. The acquired data should provide accurate and clear understanding of the textbook colors. Descriptive analysis wasused to know the textbook color types. All the textbook pictures were considered in the investigation, and their color types determined one by one. From the 154 textbook pages, 901 pictures were sampled for the analysis.

Table 1. Frequency of the colors in the textbook pictures

\begin{tabular}{lll}
\hline Colors & Frequency & Percent \\
\hline Primary Colors & 792 of 901 pictures & 87.9 \\
Secondary Colors & 733 of 901 pictures & 81.4 \\
Tertiary Colors & 412 of 901 pictures & 45.7 \\
\hline Other Colors & 886 of 901 pictures & 98.3 \\
\hline
\end{tabular}

The textbook pictures were analyzed by their colors, which were grouped into primary, secondary, and tertiary. The colors not belonging to these groups were considered as other colors. The analysis of the pictures revealed the number of times each group of colors was used in the textbook. Because each picture may contain more than one color group, the number of times a particular color group was used in the textbook was counted. According toTable 1, the primary, secondary, tertiary, and other colors in the 901 pictures were used 792, 733, 412, and 886 times, respectively. Primary colors were used in about $88 \%$ of the textbook pictures, ranking first, followed by the secondary colors. Tertiary colors were the least used.

\section{Phase II}

In phase II, the researchers' main concern was to know if gender influences the students' color preferences. The aim was to discover the male and female students' color preferences against the textbook pictures. A booklet was designed by the researchers to collect such information, and distributed among the 384 students in the selected Primary-Year-4 national school. A descriptive analysis of the data was carried out based on the students' responses.

Table 2. Color preferences among the research subjects

\begin{tabular}{lll}
\hline Color & Frequency & Percent \\
\hline Primary & 169 & 44.0 \\
Secondary & 29 & 7.6 \\
Tertiary & 186 & 48.4 \\
\hline Total & 384 & 100.0 \\
\hline
\end{tabular}

The objective of this study was to find the students' color preferences for the colors used in the textbook pictures. The responses of each student were analyzed and his/her color preference determined. The responses were organized based on the color categories, and tabulated in Table 2, which shows $48.4 \%$ responses (a majority) for the tertiary colors, i.e., the tertiary 
colors attract more attention than do the other colors. In second position, the primary colors correspond to $44.0 \%$ responses. The smallest number of responses was for the secondary colors. The tertiary colors are thus the first-choice colors among the respondents, followed by the primary and the secondary colors.

Table 3. Color preferences based on the students' gender

\begin{tabular}{llllll}
\hline \multirow{2}{*}{ Gender } & \multicolumn{3}{c}{ Color } & \multirow{2}{*}{ Total } \\
\cline { 3 - 5 } & & Primary & Secondary & Tertiary & \\
\hline \multirow{2}{*}{ Boy } & Count & 97 & 17 & 78 & 192 \\
& \% within Color & $57.4 \%$ & $58.6 \%$ & $41.9 \%$ & $50.0 \%$ \\
\hline \multirow{2}{*}{ Girl } & Count & 72 & 12 & 108 & 192 \\
& \% within Color & $42.6 \%$ & $41.4 \%$ & $58.1 \%$ & $50.0 \%$ \\
\hline
\end{tabular}

In terms of gender, the results were separately analyzed and listed for male and female students. Table 3 shows the boys more interested in the primary colors than do the girls. Almost the reverse is true for the tertiary colors. The girls and boys showed the least interest in the secondary colors.

A chi-square test of independence was conducted to discover if there is any association between gender and color preference. All the expected cell frequencies were greater than five, so the assumption of chi-square test was met. Since the chi-square test is for statistical significance and is not a measure of strength of association between two categorical variables, Cramer's $\mathrm{V}$ as the measure of association was also run.

Table 4. Chi-square test results for the association between gender and color preference

\begin{tabular}{llll}
\hline & Value & df & Asymp. Sig. (2-sided) \\
\hline Pearson Chi-Square & $9.399 \mathrm{a}$ & 2 & .009 \\
Likelihood Ratio & 9.438 & 2 & .009 \\
$\begin{array}{l}\text { Linear-by-Linear } \\
\text { Association }\end{array}$ & 8.517 & 1 & .004 \\
N of Valid Cases & 384 & \\
\hline $\begin{array}{l}\text { a. } 0 \text { cells }(0.0 \%) \\
\text { count is } 14.50 .\end{array}$
\end{tabular}

Table 5Cramer's measure of the strength of association between gender and color preference

\begin{tabular}{lcl}
\hline & Value & Approx. Sig. \\
\hline Phi & .156 & .009 \\
Cramer's V & .156 & .009 \\
Contingency Coefficient & .155 & .009 \\
\hline N of Valid Cases & 384 & \\
\hline
\end{tabular}

The results of the chi-square test and Cramer's V measure produced by the SPSS software are 
as reported in Table 4 and Table 5. Based on Table 4, all the expected cell frequencies are greater than five, and, since $\chi 2(2)=8.632, p<.05$, there is also a statistical association between gender and color preference. However, the association between gender and color preference (Table 5) is weak (Cohen, 1988) as the Cramer's V =0.149.

Table 6. Contingency table for the association between gender and color preference

\begin{tabular}{|c|c|c|c|c|c|}
\hline \multirow{2}{*}{ Gender } & & \multicolumn{3}{|l|}{ Color } & \multirow{2}{*}{-Total } \\
\hline & & Primary & Secondary & Tertiary & \\
\hline \multirow{7}{*}{ Boy } & Count & 97 & 17 & 78 & 192 \\
\hline & Expected Count & 84.5 & 14.5 & 93.0 & 192.0 \\
\hline & $\%$ within Gender & $50.5 \%$ & $8.9 \%$ & $40.6 \%$ & $100.0 \%$ \\
\hline & $\%$ within Color & $57.4 \%$ & $58.6 \%$ & $41.9 \%$ & $50.0 \%$ \\
\hline & $\%$ of Total & $25.3 \%$ & $4.4 \%$ & $20.3 \%$ & $50.0 \%$ \\
\hline & Std. Residual & 1.4 & .7 & -1.6 & \\
\hline & Adjusted Residual & 2.6 & 1.0 & -3.1 & \\
\hline \multirow{7}{*}{ Girl } & Count & 72 & 12 & 108 & 192 \\
\hline & Expected Count & 84.5 & 14.5 & 93.0 & 192.0 \\
\hline & $\%$ within Gender & $37.5 \%$ & $6.2 \%$ & $56.2 \%$ & $100.0 \%$ \\
\hline & $\%$ within Color & $42.6 \%$ & $41.4 \%$ & $58.1 \%$ & $50.0 \%$ \\
\hline & $\%$ of Total & $18.8 \%$ & $3.1 \%$ & $28.1 \%$ & $50.0 \%$ \\
\hline & Std. Residual & -1.4 & -.7 & 1.6 & \\
\hline & Adjusted Residual & -2.6 & -1.0 & 3.1 & \\
\hline \multirow{5}{*}{ Total } & Count & 169 & 29 & 186 & 384 \\
\hline & Expected Count & 169.0 & 29.0 & 186.0 & 384.0 \\
\hline & $\%$ within Gender & $44.0 \%$ & $7.6 \%$ & $48.4 \%$ & $100.0 \%$ \\
\hline & $\%$ within Color & $100.0 \%$ & $100.0 \%$ & $100.0 \%$ & $100.0 \%$ \\
\hline & $\%$ of Total & $44.0 \%$ & $7.6 \%$ & $48.4 \%$ & $100.0 \%$ \\
\hline
\end{tabular}

For detailed information and to get a good sense of the data, an analysis of the residuals through the contingency table produced by SPSS was also carried out. Here, the contingency table called the gender* color preference table is shown in Table 6. In order to more easily explain the various aspects of the contingency table, the observed counts (i.e., the "Count" rows) of the contingency table is described first. Based on the "Count" row of Table 6, out of 192 boys there were 97 who selected primary colors as their preferred colors, while among 192 girls there were 108 who preferred tertiary colors. Also, the observed counts are expressed as proportions or percentages, as shown in the next rows of the Count row. For example, the "\% within Gender" row expresses the counts observed in each cell of that row compared with the total in that row as a percentage. It means that out of 192 boys, 97 (i.e., 50.5\%) selected primary colors. In addition, the "\% within Color" row describes the percentage of the column variable (color type) that was selected by the boys or the girls. For example, $57.4 \%$ of primary color 
preferences were associated with the boys.

The "Expected Counts" (in another row)are the counts expected in each cell of the contingency table if the null hypothesis of the chi-square test was true (i.e., the counts we would expect if there was independence or no association between gender and color preference).If the two variables are independent, the observed counts and the expected counts are expected to be similar. According to the table, if there is no association between gender and color preference, there should be 85 boys who selected the primary colors (i.e., in the "Expected Count" row), but instead, 97 boys selected the primary colors (in the "Count" row). Therefore, more boys selected the primary colors than had been expected (i.e., the observed count of 97 is larger than the expected count of 84.5). On the girls' side, if there is no association between gender and color preferences, the expected count for the primary colors is 84.5 (i.e., in the "Expected Count" row), but the observed is only 72 (i.e., in the " Observed Count" row).From the analysis above, the more discrepancies between the expected counts and the observed counts, the more the model of independence would not appear to fit (i.e., it would appear that we can reject the null hypothesis).

The residuals shall now be analysed. A residual is the difference between the expected frequency and the observed frequency. The adjusted standardized residuals are used to determine which cells deviate from independence. Table 6includes both positive and negative adjusted standardized residuals. A positive adjusted standardized residual indicates higher observed frequencies than expected frequencies given the null hypothesis of independence (i.e., between gender and color preference). A negative adjusted standardized residual indicates lower observed frequencies than the expected frequencies, given the null hypothesis of independence. According to a common guideline, a cell deviates significantly from independence (i.e., evidence against the null hypothesis) when the absolute adjusted standardized residuals are greater than 2 (for small tables) or 3 (for large tables) (Agresti, Franklin, \& Klingenberg, 2016). The largest adjusted standardized residuals are for the boys who selected the primary or the tertiary colors, as well as for the girls who selected the primary and the tertiary colors. In the case of the boys selecting the primary colors, these colors were selected by 12 more than the expected if the null hypothesis (of chi-square test) was true, with 2.6 adjusted standardized residual. As to the girls who selected the primary colors, these colors were selected by 13 fewer girls than expected if the color preference was independent of gender, with -2.6 adjusted standardized residual.

\section{Discussion}

This research showed that more than $90 \%$ of the pictures in the English textbook for Malaysian Primary-Year-4 national schools are colored, and among them, 88\%useprimary colors (red, yellow, blue), 81\%usesecondary colors (orange, green, purple), and 46\%usetertiary colors (red-orange, yellow-orange, yellow-green, blue-green, blue-violet, and red-violet). There is also another group of colors in art and painting, and it includes white, black, cream, and grey. These are called natural colors, and $98 \%$ of them were used in the textbook pictures. Each textbook picture, considered as one unit, may be in all of the four mentioned color classes, i.e., the picture is a combination of primary, secondary, tertiary, and natural colors. 


\section{Ml Macrothink}

The results of this study suggest that students at this age and school level are more interested in combined colors (tertiary colors) than in primary and secondary colors. They are more inclined towards the more complex combination of colors, i.e., red-orange, yellow-orange, yellow-green, blue-green, blue-violet, and red-violet. Both genders are less interested in the secondary colors than in the other color categories. However, tertiary colors are more preferred by the girls, whereas primary colors attract the boys more. Tertiary colors are more preferred by both genders, followed by the primary colors of red, yellow, and blue. The students' least preferred colors are orange, green, and purple.

\section{Conclusion}

In this paper, the colors used inthe national school Primary-Year-4 English textbook were investigated through the perceptions of its student users. The research was designed in two phases; in the first phase, content analysis of the textbook based on the colors used in its pictures, and in the second phase, analysis of the students' color preferences. The first resource (the textbook)revealed seemingly little coordination, knowledge, or thought/consideration behind the choice of colors; its designers used more primary and secondary colors than mixed colors (tertiary colors). The second resource (the students) proved the mixed colors to be the most attractive to them by their responses to the visual questionnaire. Gender seems to influence their preferences, as revealed by the more than half of the male student population indicating their preference for primary colors.

\section{Acknowledgment}

The authors thank all members of the expert panel for their helpful comments and suggestions for this research.

\section{References}

Agresti, A., Franklin, C. A., \& Klingenberg, B. (2016). Statistics: The Art and Science of Learning from Data: Pearson.

Ansary, H., \& Babaii, E. (2002). Universal characteristics of EFL/ESL textbooks: A step towards systematic textbook evaluation. The Internet TESL Journal, 8(2). Retrieved November 17, 2011.

Bell, A. (2013). The effect of colour on audience response in theatre scenic design. Murdoch University.

Buckingham, B., \& Harrower, M. (2007). The Role of Color Saturation in Maps for Children. Cartographic Perspectives, 58. https://doi.org/10.14714/CP58.265

Cochran, W. (1977). Sampling Techniques, New York: JohnWiley. Cochran 3 Sampling Techniques1977.

Corah, N. L. (1964). Color and form in children's perceptual behavior. Perceptual and motor skills, 18(1), 313-316. https://doi.org/10.2466/pms.1964.18.1.313 
Crossley, M., \& Murby, M. (1994). Textbook provision and the quality of the school curriculum in developing countries: Issues and policy options. Comparative education, 30(2), 99-114. https://doi.org/10.1080/0305006940300203

Dey, I. (1993). Qualitative data analysis: A user friendly guide for social scientists: Routledge. https://doi.org/10.4324/9780203412497

Downe Wamboldt, B. (1992). Content analysis: method, applications, and issues. Health care for women international, 13(3), 313-321. https://doi.org/10.1080/07399339209516006

Ellis, L., \& Ficek, C. (2001). Color preferences according to gender and sexual orientation. $\begin{array}{llll}\text { Personality and Individual } \quad \text { Differences, } & 31(8), & 1375-1379 .\end{array}$ https://doi.org/10.1016/S0191-8869(00)00231-2

Elo, S., \& Kyngas, H. (2008). The qualitative content analysis process. Journal of advanced nursing, 62(1), 107-115. https://doi.org/10.1111/j.1365-2648.2007.04569.x

Fauzi, F. H. A., Jaafar, F., Ramli, W. N. R. W., \& Zain, A. M. (2015). The Behavior Patterns Toward Printed Color Medium for Students with Hearing Disabilities. Paper presented at the International Colloquium of Art and Design Education Research (i-CADER 2014). ttps://doi.org/10.1007/978-981-287-332-3_60

Gaines, K. S., \& Curry, Z. D. (2011). The inclusive classroom: The effects of color on learning and behavior. Journal of Family \& Consumer Sciences Education, 29(1), 46-57.

Graneheim, U. H., \& Lundman, B. (2004). Qualitative content analysis in nursing research: concepts, procedures and measures to achieve trustworthiness. Nurse education today, 24(2), 105-112. https://doi.org/10.1016/j.nedt.2003.10.001

Hartley, J. (2013). Designing instructional text: Routledge.

Hawley, V. A. (2009). A qualitative content analysis of the portrayal of women in. UNIVERSITY OF KANSAS.

Jalil, N. A., Yunus, R. M., \& Said, N. S. (2013). Studentsâ€าм Colour Perception and Preference: An Empirical Analysis of Its Relationship. Procedia-Social and Behavioral Sciences, 90, 575-582. https://doi.org/10.1016/j.sbspro.2013.07.128

Keser, H., \& Aydin, B. (2007). The Content Analysis of Sixth Grade Computer Textbooks. Online Submission.

Kiai, A. W. (2012). Biography of an English language textbook in Kenya: a journey from conceptualization to the classroom. University of Warwick.

Kim, D.-Y. (2010). The interactive effects of colors on visual attention and working memory: In case of images of tourist attractions.

Krippendorff, K. (2004). Reliability in content analysis. Human communication research, 30(3), 411-433. https://doi.org/10.1111/j.1468-2958.2004.tb00738.x 
Kueller, R., \& Mikellides, B. (1993). Simulated studies of color, arousal, and comfort Environmental Simulation (pp. 163-190): Springer.

Mahnke, F. H. (1996). Color, environment, and human response: an interdisciplinary understanding of color and its use as a beneficial element in the design of the architectural environment: John Wiley \& Sons.

Otto, W., \& Askov, E. (1968). The Role of Color in Learning and Instruction.

Praphamontripong, P. (2010). Textbook Formats and Visual Effects on Learning for Beginning Readers. Desk review for the World Bankâ€ $€^{\mathrm{TM}_{S}}$ Education for All Fast Track Initiative Project. Washington DC.

Riff, D., Lacy, S., \& Fico, F. (2014). Analyzing media messages: Using quantitative content analysis in research: Routledge.

Riffe, D., Lacy, S., \& Fico, F. G. (2005). Analyzing media messages: Using quantitative content analysis in research (2 ed.). Mahwah, NJ: Lawrence Erlbaum nd Associates, Publishers.

Roohani, A., \& Sharifi, M. (2015). Evaluating visual elements in two EFL textbooks. Indonesian Journal of Applied Linguistics, 4(2), 68-77. https://doi.org/10.17509/ijal.v4i2.684

Rose, G. (2007). Visual methodologies: An introduction to researching with visual materials: Sage.

Starosta, W. J. (1984). Qualitative content analysis: a Burkeian perspective.

Stempel, G. H., \& Westley, B. H. (1989). Research methods in mass communication: Prentice Hall.

Torrice, A. F., \& Logrippo, R. (1989). In my Room: Designing for and with Children: Fawcett Books.

Vetter, R., Ward, C., \& Shapiro, S. (1995). Using color and text in multimedia projections. MultiMedia, IEEE, 2(4), 46-54. https://doi.org/10.1109/93.482295

Westfall, R. S. (1962). The development of Newton's theory of color. Isis, 53(3), 339. https://doi.org/10.1086/349596 